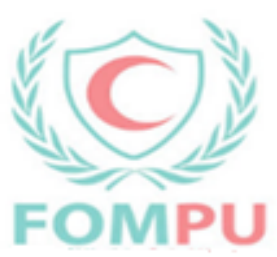

Medicine Updates

Faculty of medicine

April 2020,volume 1, issue 1 https://muj.journals.ekb.eg

dean@med.psu.edu.eg

vice_dean_postgraduate@med.psu.edu.eg

DOI:10.21608/muj.2020.25071.1008

ISSN : 2682-2741

Submitted: $3 / 3 / 2020$

Accepted : 9/3/2020

Pages:42-54

\title{
Evaluation of Cardiac Troponin I as a Non Invasive Tool for Diagnosis of the Newborns and Infants Below 6 Months with Congenital Heart Diseases
}

.Mohamed A Abdelrahman1, Hoda A Atwa2, Alaa S Abdelhamid3, Sherien A Shalaby4 Resident, Department of paediatrics and neonatology) Faculty of Medicine Suez Canal )1 University; Ismailia, Egypt

Professor, Department of paediatrics and neonatology) Faculty of Medicine Suez Canal )2 University; Ismailia, Egypt

Professor, Department of clinical pathology) Faculty of Medicine Suez Canal University; )3 Ismailia, Egypt

4 (Assistant professor, Department of paediatrics and neonatology) Faculty of Medicine Suez Canal University; Ismailia, Egypt.

\section{Abstract}

\section{Background}

Congenital heart diseases accounts for nearly one third of all major congenital anomalies. Different modalities for diagnosis of CHD are available, in spite of that only $73 \%$ can be diagnosed before discharge from hospital, while $27 \%$ discharged without diagnosis. There is an increasing need for new diagnostic modalities to help early diagnosis and screening of CHD, biomarkers as cardiac troponin I represents an excellent choice.

\section{$\underline{\underline{\text { Aim }}}$}

The aim of this study is to find new, easy and noninvasive diagnostic modalities for earlier detection of congenital heart diseases. 


\section{Patients /Methods}

The study was case control study. The study involved 50 cases. cases will be divided into 2 main groups: group (1) 25 patients with congenital heart diseases confirmed by echocardiography, group (2) (control) 25 healthy newborns and infants, patients with CHD in group (1) was further divided into 2 subgroups: group (1a) patients with simple shunts, group (1b) patients with combined defects. Each case was subjected to complete history, physical examination, and peripheral blood samples were withdrawn and cardiac troponin I level was measured.

\section{$\underline{\underline{\text { Results }}}$}

Serum level of cardiac troponin I (cTnI) was higher in the diseased group compared to the control group, and is higher in patients with complex defects compared to patients with simple shunts. The sensitivity of the test was $72 \%$ and the specificity was $92 \%$.

\section{Conclusion}

Serum cTnI level was found to have a statistically significant association with congenital heart disease, being higher in complex defects than simple shunts.

Key words: cTnI, CHD, biomarkers.

\section{Introduction:}

Congenital heart diseases (CHD) accounts for nearly one third of all major congenital anomalies, its incidence increased from 0.6 per 1000 live births at 1930 to 9.1 per 1000 live births after $1995^{(\mathbf{1})}$, in Egypt the prenatal incidence of moderate and severe cardiac anomalies reaches 19 per 1000 live children ${ }^{(2)}$. Also there is an increase in the median age of patients with CHD, it was 11 years in 1985,17 years in 2000 and reach 25 years in 2010, the proportion of adults with CHD increased from $54 \%$ in 2000 to $66 \%$ in $2010^{(3)}$.

This increase is mainly due to increased awareness about CHD, development of new modalities for diagnosis, improved care and decreased mortality ${ }^{(4)}$, also there is increased incidence due to increased maternal age ${ }^{(5)}$, excessive body 
mass index (BMI) and maternal smoking during pregnancy ${ }^{(6,7)}$.

Different modalities for diagnosis of CHD are available, in spite of that only $73 \%$ of cases can be diagnosed before discharge from hospital, while $27 \%$ of cases discharged from hospital without diagnosis ${ }^{(\mathbf{8})}$.

This delay in diagnosis strongly affects preoperative condition of the patient, which in turn affects postoperative progress and mortality, so early diagnosis of CHD is essential to decrease mortality rate ${ }^{(9,10)}$. There is an increasing need for new diagnostic modalities to help early diagnosis and screening of CHD, biomarkers as cardiac troponin I represents an excellent choice as it is easy test can be done wherever, needs no special centers as catheterization, no skilled cardiologist as echocardiography ${ }^{(11)}$.

Recent studies showed that variable biomarkers can be used as indicators for pressure and volume overload that occur in CHD such as cardiac troponin I (cTnI), cardiac troponin $\mathrm{T}(\mathrm{cTnT}), \mathrm{N}$-terminal pro brain natriuretic peptide (NTproBNP), heart-type fatty acid binding protein (H-FABP) and high-sensitivity $\mathrm{C}$ reactive protein (Hs-CRP) ${ }^{(12,13,14)}$.

Troponin complex comprises troponin $\mathrm{C}$, troponin $\mathrm{T}$ and troponin I; of these cardiac troponins $\mathrm{T}$ and $\mathrm{I}$ are myofibrillar regulatory proteins which are highly specific to cardiac tissue and only small portions present in cytosol while the majority is bound to contractile proteins. Cardiac troponin I can be used as a marker for cardiac injury with high sensitivity (95.5\%), specificity (97.1\%), positive predictive value $(96 \%)$ and negative predictive value $(99.1 \%){ }^{(15,16)}$. Also cardiac troponin I can be used as a useful biomarker for evaluating myocardial damage in CHD caused by volume and pressure overload ${ }^{(17,18,19)}$.

In this study researcher will evaluate cardiac troponin I as a diagnostic tool for CHD aiming to facilitate early diagnosis of CHD.

\section{Patients \& Methods:}

The study was case control study. The study population was sampled from neonates and infants (aging $<6$ month) admitted to Suez Canal University Hospital's neonatal intensive care unit (NICU), pediatric intensive care unit (PICU) and pediatrics inpatient from September 2015 to March 2016. Simple 
random sampling was used. every patient admitted to the SCU Hospital eligible for the study`s criteria was chosen. Exclusion criteria includes any neonate suggested to be exposed to severe perinatal asphyxia (Apgar score $<4$ in $1^{\text {st }}$ and $5^{\text {th }}$ minute), neonates and infants below 6 months with signs of severe non cardiac illness (as septic shock) and patients with myocardial diseases (as toxic myocarditis).

The study involved 50 cases. cases were divided into 2 main groups : group 1 (cases) consisted of 25 patients with congenital heart diseases confirmed by echocardiography, group 2 (control) consisted of 25 healthy newborns and infants who were age and sex matching the cases, they were collected from newborns and infant admitted to SCU hospital for non-cardiac cause, patients with CHD in group (1) was further divided into 2 subgroups: group (1a) patients with simple shunts (ASD, VSD , PDA or combinations of these lesions ), group (1b) patients with combined defects (others).

Detailed medical history was taken, detailed physical examination and basic laboratory tests were performed for each case. Troponin I was evaluated using PATHFAST ${ }^{\circledR}$ Troponin I (Mitsubishi, Japan). $1 \mathrm{ml}$ of blood was collected using standard sampling tubes, the collected samples was centrifuged to remove the coagulated or packed cells within 60 minutes after collection, samples was frozen at $-20^{\circ} \mathrm{c}$ or lower, freeze only once, Storage and assays were performed as per the manufacturer's protocol.

The data was recorded in a case sheet, the case sheet was divided into five sections: personal data, perinatal data, clinical data, laboratory data and radiological data including chest $\mathrm{x}$-ray and echocardiography.

Statistical analysis was done by Statistical Package for Social Science (SPSS) for windows version 22. The distribution of variables was compared with the normal distribution by means of the Kolmogorov-Smirnov goodness-of-fit test. The differences between groups in non-parametric quantitative data were assessed by Mann-Whitney $U$-test and Kruskal Wallis test. Chi-square test was used for testing significant differences of qualitative variables. For cross-tables were the number of cells whose expected count less than 5 were $>20 \%$ of cells, Fisher's Exact tests and Exact $p$ value for Chi-square test were used. ROC curve was used to assess the sensitivity, specificity and accuracy of cTnI as a marker of myocardial injury in patients with CHD. For all statistical analysis the level of 
significance considered was $<0.05$.

\section{$\underline{\underline{\text { Results }}}$}

Table 1. Mean value and standard deviation of cTnI in different groups.

\begin{tabular}{|l|c|c|c|}
\hline & Mean \pm Std. Deviation & Range & \multirow{2}{*}{ P value } \\
\cline { 1 - 3 } Normal (n=25) & $0.01 \pm 0.00 \mathrm{ng} / \mathrm{ml}$ & $0.006-0.014$ & $0.01-0.77$ \\
\cline { 1 - 2 } Simple CHD (n=14) & $0.23 \pm 0.32 \mathrm{ng} / \mathrm{ml}$ & $0.001 *$ \\
\cline { 1 - 2 } Complex CHD (n=11) & $0.99 \pm 0.19 \mathrm{ng} / \mathrm{ml}$ & $0.78-1.32$ & \\
\hline
\end{tabular}

* Statistically significant at $\mathrm{p}<0.05$, Mann-Whitney U test

This table shows the mean value \pm standard deviation of $\mathrm{cTnI}$ in the different groups. It was higher in the neonates and infants with CHD than in healthy neonates and infants in the control group being higher in patients with complex defects than in patients with simple shunts. (P value $=<0.001)$.

Table 2. Distribution of cTnI positive and negative values among the two groups

\begin{tabular}{|c|c|c|c|c|}
\hline & & \multicolumn{2}{|c|}{ CTnI $($ cutoff value $=0.0135 \mathrm{ng} / \mathrm{ml})$} & \multirow{4}{*}{$\begin{array}{l}\text { P value } \\
<0.001\end{array}$} \\
\hline & & Positive & Negative & \\
\hline \multirow[t]{2}{*}{ Group } & CHD & $18(36.0 \%)$ & $7(14.0 \%)$ & \\
\hline & Normal & $2(4.0 \%)$ & $23(46.0 \%)$ & \\
\hline
\end{tabular}

* Statistically significant at $\mathrm{p}<0.05$, Fisher's Exact Test

This table shows the distribution of cTnI positive and negative values (at cutoff value $0.0135 \mathrm{ng} / \mathrm{ml}$ ) among the diseased and control group. Sensitivity of the test was $72 \%$, specificity of the test was $92 \%$, positive predictive value was $90 \%$ and negative predictive value was $76.7 \%$.

Table 3. Comparison of cTnI level in different classes of heart function according to Ross's classification ${ }^{(20)}$.

\begin{tabular}{|c|c|c|c|}
\hline Heart failure & Mean \pm Std. Deviation & Range & \multirow{3}{*}{$P$ value } \\
\hline No HF $(n=4)$ & $0.30 \pm 0.33 \mathrm{ng} / \mathrm{ml}$ & $0.01-0.63$ & \\
\hline Mild HF (n=9) & $0.40 \pm 0.51 \mathrm{ng} / \mathrm{ml}$ & $0.01-1.32$ & \\
\hline Moderate HF $(n=10)$ & $0.73 \pm 0.41 \mathrm{ng} / \mathrm{ml}$ & $0.01-1.27$ & \multirow[t]{2}{*}{$0.04 *$} \\
\hline Severe HF $(n=2)$ & $1.03 \pm 0.07 \mathrm{ng} / \mathrm{ml}$ & $0.99-1.09$ & \\
\hline
\end{tabular}

* Statistically significant at $\mathrm{p}<0.05$, Mann-Whitney U test 
This table shows comparison of cTnI level in different classes of heart function. cTnI level is affected by the grade of heart failure being highest in patients with severe HF and lowest in patients with no HF. $(P$ value $=0.04)$

Table 4. Multiple linear regression for factors affecting cTnI level.

\begin{tabular}{|c|c|c|c|c|c|c|c|}
\hline \multirow[b]{2}{*}{ Model } & \multicolumn{2}{|c|}{$\begin{array}{l}\text { Unstandardized } \\
\text { Coefficients }\end{array}$} & \multirow{2}{*}{\begin{tabular}{|l}
$\begin{array}{l}\text { Standardized } \\
\text { Coefficients }\end{array}$ \\
Beta
\end{tabular}} & \multirow[b]{2}{*}{$\mathrm{T}$} & \multirow[b]{2}{*}{ P value } & \multicolumn{2}{|c|}{$95 \%$ Confidence Interval for $\beta$} \\
\hline & $B$ & Std. Error & & & & Lower Bound & Upper Bound \\
\hline (Constant) & 0.455 & 0.260 & & 1.751 & 0.087 & -0.068 & 0.978 \\
\hline Length & -0.094 & 0.039 & -0.284 & -2.418 & 0.020 & -0.172 & -0.016 \\
\hline Age in months & -0.062 & 0.023 & -0.254 & -2.754 & 0.008 & -0.108 & -0.017 \\
\hline$\overline{\mathrm{HF}}$ & 0.252 & 0.054 & 0.547 & 4.706 & $<0.001$ & 0.144 & 0.360 \\
\hline
\end{tabular}

This table show multiple linear regression for factors affecting cTnI level. Linear regression analysis was done for predictors of CTnI. Factors entered into the model were heart failure, age, weight, height and antifailure treatment. According to the regression analysis model heart failure, age and length were found as predictors for $\mathrm{cTnI}$ positivity where heart failure showed the highest effect on $\mathrm{cTnI}(=0.547, \mathrm{p}$ value $<0.001)$ followed by length $(\beta=-$ 0.284 , $p$ value $=0.020)$ then age $(\beta=-0.254$, $p$ value $=0.008)$.

\section{$\underline{\underline{\text { Discussion }}}$}

Congenital heart diseases are the most common congenital anomalies, approximately $73 \%$ of infants with CHD are diagnosed before discharge from hospital after birth and $27 \%$ have late diagnosis after discharge with median age of detection 88 days ${ }^{(\mathbf{8 , 2 1})}$. Late detection of congenital heart diseases leads to 52\% more hospital admissions, 18\% more hospitalized days, 35\% higher inpatient costs and $1.8 \%$ potentially preventable deaths ${ }^{(\mathbf{2 1})}$.

A highly sensitive cTnI assay has been developed to detect very low levels of cTnI even trace leakages from the unbound cytosolic pool. Such low levels of cTnI in serum might reflect early myocardial cell death as well as reversible injury. Thus, the cTnI assay is a very useful tool for detecting subclinical heart diseases at the initial presentation ${ }^{(22)}$. 
In this study we evaluate new diagnostic modality to help early diagnosis and screening of CHD, cardiac troponin I represents an excellent choice as it is an easy test that can be done wherever, needs neither special centers nor skilled cardiologist.

We studied 50 neonates and infant, 25(50\%) healthy newborns and infants, 14(28\%) newborns and infants with simple shunts (ASD, VSD, PDA or combinations of these lesions) and $11(22 \%)$ newborns and infants with combined defects (others). Males represented $40 \%$ while females $60 \%$ in both groups. The mean age of the control group and diseased group which was 3.3 and 3.2 months respectively. Also the mean age of the group with simple shunts and the group with combined defects was 3.1 and 3.2 months respectively.

In the present work, the mean value of cardiac troponin I (cTnI) was higher in the diseased group compared to the control group, and is higher in patients with complex defects compared to patients with simple shunts. which is in agreement with the cited study of Sugimoto et al. (2011) ${ }^{(17)}$ who studied 350 healthy children, 30 children with ASD and 32 children with VSD and was the first to show that cTnI levels are higher in children with CHD than control group and that cTnI level in children with VSD was higher than its level in children with ASD.

Also Uner et al. (2014) ${ }^{(14)}$ studied 50 children with acyanotic CHD, 16 children with cyanotic CHD and 38 healthy children as a control group and reported that cTnI was found to be statistically significantly higher in the patient group than the control group, in another literature published by Eerola et al. (2013) in which they studied 78 children with CHD with volume overload, 60 children with CHD with pressure overload and 74 healthy controls, cTnI was measured at baseline prior to treatment and 6 months after treatment. They reported that $\mathrm{cTnI}$ release is more frequently associated with pressure overload than volume overload and resolves after treatment in most children.

This can be explained by what was previously published by Galderisi (2007) ${ }^{\text {(23) }}$ who reported that both ventricular hypertrophy and myocardial stretching can inhibit myocardial perfusion and that an increase in pressure inside the cardiac walls due to stretching can disturb the coronary microcirculation and this is what happen in patients with CHD with volume and pressure overload. Also Petersen et al. (2007) ${ }^{(24)}$ reported that ventricular hypertrophy lead to reduced myocardial 
perfusion reserve that was in proportion to the magnitude of hypertrophy.

To add a further depth to the findings of the current study we use ROC curve analysis to define the diagnostic performance of cTnI as a marker of CHD. We were interested in proposing a cut-off value of cTnI that could be used as a predictor of the presence of CHD. The ROC curve analysis showed that area under curve for cTnI was 0.89 . The highest diagnostic accuracy was achieved with a chosen cut-off for cTnI of $0.0135 \mathrm{ng} / \mathrm{ml}$ (sensitivity of $72 \%$, specificity of 92\%). In another literature previously published by Sugimoto et al. (2011) ${ }^{(17)}$ who studied 350 healthy children as a control group and 62 children with CHD, they reported that the $99^{\text {th }}$ percentile of $\mathrm{cTnI}$ level in the healthy group was 0.014 $\mathrm{ng} / \mathrm{ml}$.

In our study, it was found that at cutoff value of $0.0135 \mathrm{ng} / \mathrm{ml}$, cTnI was positive in 18 children in the diseased group $(\mathrm{n}=25)$ and in 2 neonates in the control group $(\mathrm{n}=25)$, with sensitivity about $72 \%$ and specificity about $92 \%$. Uner et al. (2014) ${ }^{(14)}$ reported that of the studied 66 children with CHD there was 34 children with cTnI positive, with sensitivity of about $52 \%$. The higher sensitivity in our study is explained by the younger age of the children in our study (0-6 months) than those in their study ( 3 months- 16 years).

Also Eerola et al. (2014) ${ }^{(19)}$ reported that sensitivity of the test was about $50 \%$, the higher sensitivity in our study is explained by the fact that their study involves only one type of CHD (hypoplastic left heart syndrome) while our study involves several types of CHD either simple shunts and complex defects.

In the current study there was 2 neonates in the control group with cTnI positive (cut off value $=0.0135 \mathrm{ng} / \mathrm{ml}$ ), these 2 neonates aged 2 days and 5 days. They were normal without any CHD confirmed by echocardiography. And this finding is in agreement with the results found by Sugimoto et al. $(2011){ }^{(17)}$ who reported that there was a relationship between the cTnI level and age in the healthy group and that neonates show higher levels of cTnI, also Eerola et al. (2014) ${ }^{(19)}$ reported that among the control group enrolled in the study there was one neonate showing cTnI positive. In another literature Eerola et al. (2013) ${ }^{(18)}$ found that there was one neonate with cTnI positive in the healthy control group. 
This can be explained by what was published by Almeida et al. (2011) who studied 225 full term neonates with Apgar score more than 8 at $1 \mathrm{~min}$, they found that $\mathrm{cTnI}$ increases from $0.004 \mathrm{ng} / \mathrm{ml}$ to $0.058 \mathrm{ng} / \mathrm{ml}$ by the age of 3 days falling to $0.030 \mathrm{ng} / \mathrm{ml}$ by 10 days and this due to the early transition from fetal to neonatal circulation with increased systemic pressure and decreased pulmonary pressure which induced programmed myocyte cell death that plays an important role in determination of the number and distribution of ventricular and interventricular muscle cells.

In the present work, it was found that cTnI level is affected by the grade of heart failure. In patients with no HF the mean value of cTnI level was $0.3 \pm 0.33$ $\mathrm{ng} / \mathrm{ml}$, in patients with mild $\mathrm{HF}$ it was $0.4 \pm 0.51 \mathrm{ng} / \mathrm{ml}$, in patients with moderate $\mathrm{HF}$ it was $0.73 \pm 0.41 \mathrm{ng} / \mathrm{ml}$, and in patients with severe $\mathrm{HF}$ it was $1.03 \pm 0.07$ $\mathrm{ng} / \mathrm{ml}$. Linear regression analysis for factors affecting $\mathrm{cTnI}$ revealed significant positive correlation between $\mathrm{cTnI}$ and heart failure. This is consistent with the results found by Zhou et al. (2014) ${ }^{(13)}$ who studied 22 children with CHD and heart failure, 25 children with CHD and 25 healthy children. They reported that cTnI level and rate of positivity was significantly higher in patients with CHD and heart failure than those with CHD without heart failure.

In the current study, linear regression analysis for factors affecting cTnI revealed significant negative correlation between cTnI level and age of patient. This is in agreement with the results reported by Eerola et al. (2013) ${ }^{\text {(18) }}$ who found that the children with positive cTnI were significantly younger than those with negative cTnI.

In addition, linear regression analysis revealed significant negative correlation between cTnI level and length of patient. The degree of length affection in the patient with CHD is affected by the type of the CHD being larger in the complex $\mathrm{CHD}^{(26)}$. And as we mentioned above the cTnI level is affected by type of CHD being higher in patients with complex defects.

Studies on cTnI and other biomarkers of CHD are limited especially in developing countries, however some studies had developed in different target population, as in the study done by the Egyptian authors Hafez et al. (2015) ${ }^{(27)}$ who studied 40 children (1 month to 12 years) with acyanotic CHD, 40 children with cyanotic CHD and 40 healthy children. They reported that cTnI was significantly higher in diseased group compared to control group and that the sensitivity of the test was $80 \%$. 
Nassef et al. (2014) ${ }^{(28)}$ studied 60 children with acyanotic CHD (aged 1-4 years), 60 children with cyanotic CHD and 30 healthy children, they found that TNF- $\alpha$, IL-6, CRP, troponin T, CK-MB is significantly higher in patients with CHD than in control group.

There were a number of limitations to our study. First, the reference value of cTnI in the neonatal period is higher than infancy and childhood, with lack of studies about this. More studies is needed to define the reference values of cTnI throughout the neonatal period.

Second, the unavailability of pediatric cardiac catheterization at our hospital prevents us from assessing the effect of specific hemodynamics on cTnI level

Finally, the lack of financial resources prevents us from studying more than one biomarker and comparing their results to assess the effect of their individual or simultaneous use.

\section{Conclusion}

In conclusion, we have shown that serum cTnI level was found to have a statistically significant association with congenital heart disease, being higher in complex defects than simple shunts. Sensitivity of the test was $72 \%$, specificity of the test was $92 \%$. cTnI level was affected by the grade of heart failure being highest in patients with severe HF and lowest in patients with no HF with statistically significant difference. Also cTnI level showed statistically significant negative correlation with age. The use of cTnI may provide us with additional tool for earlier detection of CHD. 


\section{$\underline{\underline{\text { References }}}$}

1. Van der Linde D, Konings EE, Slager MA, et al. Birth prevalence of congenital heart disease worldwide: a systematic review and metaanalysis. J Am Coll Cardiol 2011; 58(21), 2241-2247.

2. Torky H, Anwar A, Elebrashy A, et al. Incidence of antenatal moderate and severe congenital cardiac anomalies in Cairo (a multi-center retrospective study). Pregnancy Hypertens 2016; 6(2), 126-129.

3. Marelli AJ, Ionescu-Ittu R, Mackie AS, et al. Lifetime prevalence of congenital heart disease in the general population from 2000 to 2010 . Circulation 2014; 130(9), 749-756.

4. Khairy P, Ionescu-Ittu R, Mackie AS, el al. Changing mortality in congenital heart disease. J Am Coll Cardiol 2010; 56(14), 1149-1157.

5. Ooki S. Maternal age and birth defects after the use of assisted reproductive technology in Japan, 2004-2010. Int J Womens Health 2013; 5, 65-77.

6. Madsen NL, Schwartz SM, Lewin MB, et al. Prepregnancy body mass index and congenital heart defects among offspring: a population-based study. Congenit Heart Dis 2013; 8(2), 131-41.

7. Feng Y, Yu D, Yang L, et al. Maternal lifestyle factors in pregnancy and congenital heart defects in offspring: review of the current evidence [online]. Ital J Pediatr 2014; 40, 85. Available from:

http://www.ijponline.net/content/40/1/85 [Accessed 23 Aug 2015].

8. Meberg A. congenital heart defects through 30 years [online]. Ojped 2012; 2, 219-227. Available from: http://file.scirp.org/Html/22931.html [Accessed 15 Aug 2015].

9. Abid D, Elloumi A, Abid L, et al. Congenital heart disease in 37,294 births in Tunisia: birth prevalence and mortality rate. Cardiol Young 2014; 24(5), 866-871.

10.Eckersley L, Sadler L, Parry E, et al. Timing of diagnosis affects mortality in critical congenital heart disease [online]. Arch Dis Child 2015; article ID: 307691. Available from: http://www.ncbi.nlm.nih.gov/pubmed/26130379 [Accessed 10 Aug 2015].

11. Sugimoto M, Kuwata S, Kurishima C, et al. Cardiac biomarkers in children with congenital heart disease. World J Pediatr 2015; 11(4), 309315 .

12.Tarkowska A, Furmaga-Jablonska W. The evaluation of diagnostic role of cardiac troponin $\mathrm{T}(\mathrm{cTnT})$ in newborns with heart defects [online]. ScientificWorldJournal 2012; article ID 682538. Available from: http://www.ncbi.nlm.nih.gov/pmc/articles/PMC3324289/ [Accessed 25 April 2015].

13.Zhou FJ, Zhou CY, Tian YJ, et al. Diagnostic value of analysis of HFABP, NT-proBNP, and cTnI in heart function in children with congenital 
heart disease and pneumonia. Eur Rev Med Pharmacol Sci 2014; 18(10), 1513-1516.

14.Uner A, Dogan M, Ay M, et al. The evaluation of serum N-terminal prohormone brain-type natriuretic peptide, troponin-I, and high-sensitivity $\mathrm{C}$-reactive protein levels in children with congenital heart disease. Hum Exp Toxicol 2014; 33(11), 1158-1166.

15. Voicu S, Sideris G, Deye N, et al. Role of cardiac troponin in the diagnosis of acute myocardial infarction in comatose patients resuscitated from outof-hospital cardiac arrest. Resuscitation 2012; 83(4), 452-458.

16.Liebetrau C, Weber M, Tzikas S, et al. Identification of acute myocardial infarction in patients with atrial fibrillation and chest pain with a contemporary sensitive troponin I assay. BMC Med 2015; 13, 169.

17.Sugimoto M, Ota K, Kajihama A, et al. Volume overload and pressure overload due to left to right shunt induced myocardial injury. Evaluation using a highly sensitive cardiac Troponin-I assay in children with congenital heart disease. Circ J 2011; 75(9), 2213-2219.

18.Eerola A, Jokinen EO, Savukoski TI, et al. Cardiac troponin I in congenital heart defects with pressure or volume overload. Scand Cardiovasc J 2013; 47(3), 154-159.

19.Eerola A, Poutanen T, Savukoski T, et al. Cardiac troponin I, cardiac troponin-specific autoantibodies and natriuretic peptides in children with hypoplastic left heart syndrome. Interact Cardiovasc Thorac Surg 2014; $18(1), 80-85$.

20.Ross RD. The Ross classification for heart failure in children after 25 years: a review and an age-stratified revision. Pediatr Cardiol 2012; 33(8), 1295-1300.

21.Peterson C, Dawson A, Grosse SD, et al. Hospitalizations, costs, and mortality among infants with critical congenital heart disease: how important is timely detection. Birth Defects Res A Clin Mol Teratol 2013; 97(10), 664-672.

22.Melanson SE, Morrow DA, Jarolim P. Earlier detection of myocardial injury in a preliminary evaluation using a new troponin I assay with improved sensitivity. Am J Clin Pathol 2007; 128(2), 282-286.

23. Galderisi $\mathrm{M}$. Epicardial coronary vessels and coronary microcirculation in pressure overload hypertrophy: a complex interaction. Am J Hypertens 2007; 20(3), 285-286.

24.Petersen SE, Jerosch-Herold M, Hudsmith LE et al. Evidence for microvascular dysfunction in hypertrophic cardiomyopathy: new insights from multiparametric magnetic resonance imaging. Circulation 2007; 115(18), 2418-2425.

25.Almeida CM, Carrapato MR, Pinto F. Biochemical markers of neonatal 
myocardial dysfunction. J Matern Fetal Neonatal Med 2011; 24(4), 568573.

26.Daymont C, Neal A, Prosnitz A, et al. Growth in children with congenital heart disease. Pediatrics 2013; 131(1), e236-242.

27.Hafez MO, Morsy SM, Mahfoz RA, et al. Myocardial Injury in Children with Unoperated Congenital Heart Diseases[online]. Cardiol Res Pract 2015; article ID: 104818. Available:

http://www.ncbi.nlm.nih.gov/pmc/articles/PMC4243331 [accessed 13 aug 2016]

28.Nassef YE, Hamed MA, Aly HF (2014) Inflammatory cytokines, apoptotic, tissue injury and remodeling biomarkers in children with congenital heart disease. Indian J Clin Biochem 2014; 29(2), 145-149. 